\title{
Effects of Grid Disturbances on Current Source Rectifier Controlled by FCS-MPC Algorithm
}

\author{
A. Godlewska \\ Department of Power Electronics and Electric Drives, Bialystok University of Technology, \\ Białystok, Poland
}

Received June 07, 2018; Accepted September 30, 2018

Abstract: Nowadays, the increasing number of non-linear loads influences the grid, causing grid voltage disturbances. These disturbances may be very dangerous forthe equipmentand can create faults in converterbehaviour. However, the rightcontrol algorithm can improvethe reliability of the work. For a current source rectifier, the finite control set model predictive control has been proposed. This method is very flexible because of the variety of the possible cost function forms. It has been examined under grid voltage disturbed by the higher harmonics and the voltage drop. Simulation results prove the ability to damp the distortions and to ensure the unity power factor. Summing up, the algorithm is a very good solution for use in applications such as battery charging, active power filtering and low-voltage direct current load feeding.

Keywords: active front end • current source rectifier • model predictive control • active damping

\section{Introduction}

In recent years, the electric power system has endured fundamental changes because of the rise of renewable power generators and non-linear loads connected to the grid. As a result, both the system and the load are in danger caused by imbalanced grid voltages. Some ideas of the compensation and mitigation of the disturbances are presented in the works of Ibrahim and EL-Fouly (2017), Lammert et al. (2014), Yuan et al. (2017).

The current source rectifier, shown in Fig. 1, may introduce additional disturbances in case of improper control with no filter oscillation damping. In linear control methods, there are several means, such as the active damping algorithm proposed by Li et al. (2007) or the special transistor switching pattern proposed by Naguib and Lopes (2009), to reduce oscillations. Other ways of solving this problem are the apparent power compensation approach provided by Salo and Tuusa (2000) and the active and reactive power compensation approach of Noguchi and Sano (2007).

Another approach is the use of predictive control. The basis of the method is a cost function that is minimised to get the lowest errors of the predicted values. The works of Correa et al. (2009) and Zavala et al. (2013) use reactive power and direct current (DC) in the equation to control the current and provide unity power factor. Prediction of the grid and DC current has been shown by Michalik et al. (2016) and Feroura et al. (2017). All these methods differ from each other depending on the predicted physical quantity and the construction of the cost function. Very important components of the cost function are the weighting factors, explained in Cortes et al. (2009), Falkowski et al. (2017), Falkowski and Sikorski (2016), Godlewska et al. (2017).

One of the biggest problems to solve is to provide reliable converter behaviour under disturbed grid voltage. There is no possibility to predict the voltage disturbances and, therefore, the algorithms may be acting improperly. 


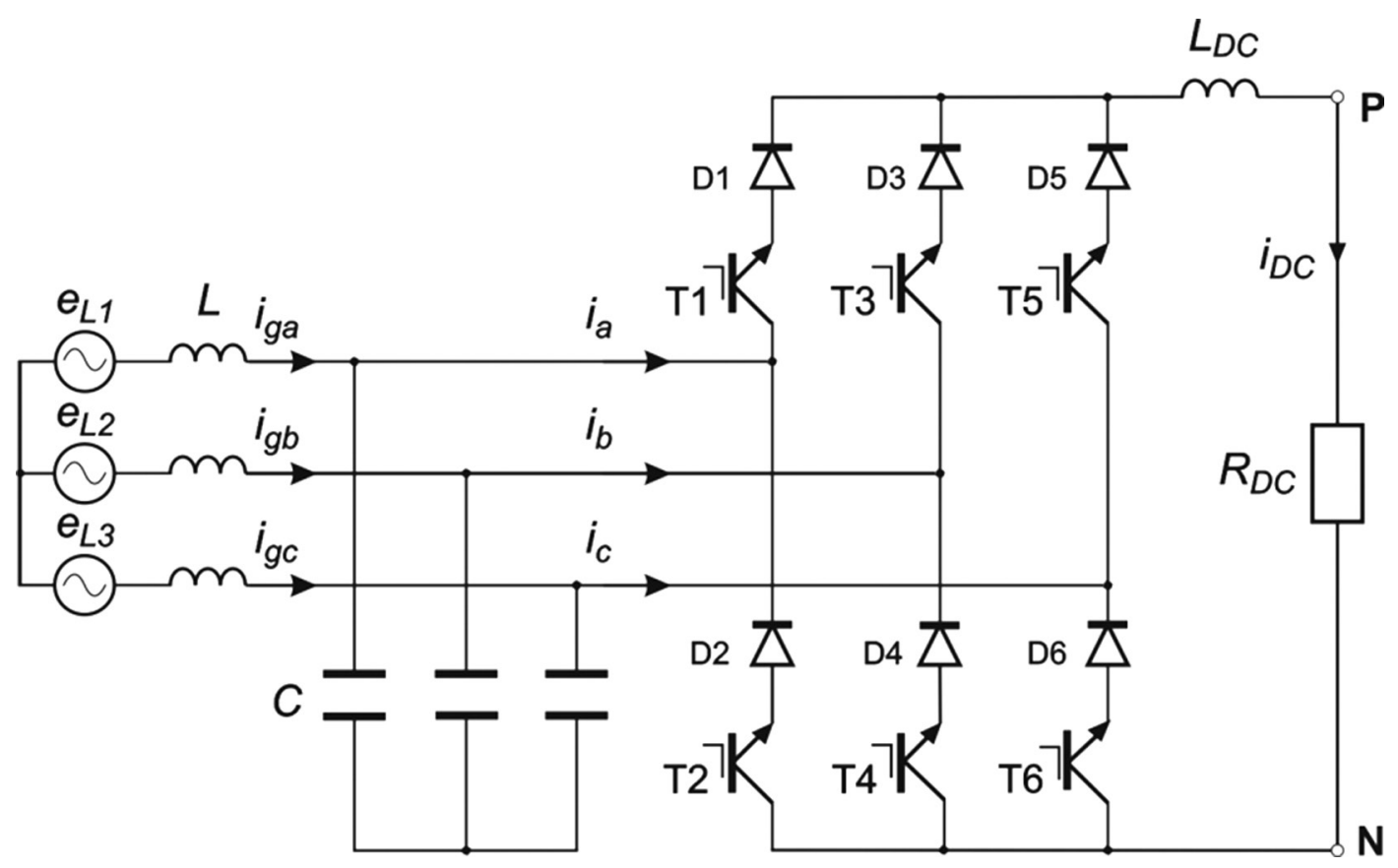

Fig. 1. Current source rectifier topology

The paper presents a novel finite control set model predictive control (FCS-MPC) method and proves that this method is insensitive for voltage drops and higher harmonics. Moreover, the algorithm causes the damping of the harmonics, which means that distortions of the grid current are smaller than distortions of the grid voltage.

\section{Mathematical model of the current source rectifier}

Simplifying the converter analysis, it was chosen to define the $x y$ reference frame. It rotates with the grid voltage pulsation $\omega_{g}=d \vartheta_{g} / d t$. The transformation from a three-phase to an $x y$ coordinate system is described by Eq. (1), which presents the converter current vectors.

$$
\boldsymbol{i}_{x y}=e^{-j \omega_{g} t} \frac{1}{\sqrt{3}}\left[\begin{array}{lll}
\mathbf{1} & \boldsymbol{a} & \boldsymbol{a}^{\mathbf{2}}
\end{array}\right]\left[\begin{array}{c}
i_{a} \\
i_{b} \\
i_{c}
\end{array}\right]=\left\{\begin{array}{c}
i_{D C} e^{j\left(n \frac{\pi}{3}-\frac{\pi}{6}-\omega_{g} t\right)} \\
0
\end{array}\right.
$$

where:

$i_{D C} e^{j\left(n \frac{\pi}{3}-\frac{\pi}{6}\right)}$ is the active vectors in switching states with $\mathrm{n}=1,2, \ldots, 6$ at time $t=0$ (Fig. 2); 0 indicates zero vectors, obtained by shortcut in one of the rectifier branches.

Equations (2) and (3) express the circuit of the input filter in the $x y$ reference frame.

$$
\begin{gathered}
\boldsymbol{e}_{g x y}=\boldsymbol{u}_{c x y}+j \omega_{g} L \boldsymbol{i}_{g x y}+L \frac{d \boldsymbol{i}_{g x y}}{d t} \\
\boldsymbol{i}_{g x y}=\boldsymbol{i}_{x y}+j \omega_{g} C \boldsymbol{u}_{c x y}+C \frac{d \boldsymbol{u}_{c x y}}{d t}
\end{gathered}
$$


where:

$\boldsymbol{e}_{g x y}-$ grid voltage vector,

$u_{c x y}$ - capacitor voltage vector and

$i_{g x y}-$ grid current vector.

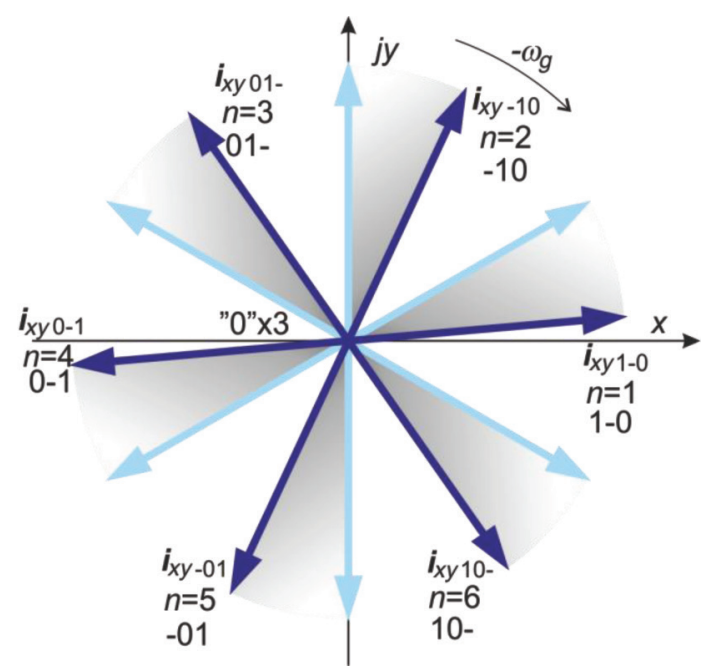

Fig. 2. Converter current vectors

The rectifier output voltage $u_{D C}$ is described by Eq. (4).

$$
u_{D C}=R_{D C} i_{D C}+L_{D C} \frac{d i_{D C}}{d t}
$$

The filter circuit influences the DC voltage in a manner explained in Eq. (5).

$$
u_{D C}=\left[\begin{array}{lll}
u_{c a} & u_{c b} & u_{c c}
\end{array}\right]\left[\begin{array}{l}
S_{a} \\
S_{b} \\
S_{c}
\end{array}\right]
$$

where:

$u_{c a}, u_{c b}, u_{c c}$ - filtering capacitor phase-to-phase voltages,

$S_{a}, S_{b}, S_{c}$ - transistor states in branches: 1 when upper is turned on, -1 when lower is on and 0 when both are switched off.

\section{FCS-MPC approach}

The proposed predictive algorithm is based on a cost function that is minimised to obtain the smallest regulation errors of the controlled values. Those values are the DC current as well as the $x$ and $y$ components of the capacitor voltage vector. The cost function is defined by Eq. (6).

$$
J=w_{u x}\left|\varepsilon_{u x}\right|+w_{u y}\left|\varepsilon_{u y}\right|+\left|\varepsilon_{D C}\right|
$$

where $w_{u x}$ and $w_{u y}$ are the weighting factors. 
Error is calculated by subtracting the predicted value from the reference value. Reference values are assumed to be constant during one sampling time. Equations (7)-(9) express the regulation errors.

$$
\begin{aligned}
& \varepsilon_{u x}=u_{c x}^{*}-u_{c x}(k+1) \\
& \varepsilon_{u y}=u_{c y}^{*}-u_{c y}(k+1) \\
& \varepsilon_{D C}=i_{D C}^{*}-i_{D C}(k+1)
\end{aligned}
$$

The algorithm calculates the predicted values of the filter voltage components and the DC current for all possible switching states. Then, those values are used to receive the cost function, and the smallest value of the cost function indicates which transistors should be turned on.

The main aim of the control system is to provide minimisation of grid current ripples and enable power factor correction by influencing the capacitor voltage vector components. It is possible due to the orientation of the reference frame $x y$ on the grid voltage vector $\left(\boldsymbol{e}_{g x y}=e_{g x}\right)$. The achievement of the unity power factor is possible when the grid current vector has no $y$ component, which means $i_{g y}=0$. As shown in Eq. (3), the value of the capacitor voltage vector influences the grid current vector; thus, prediction of the capacitor voltage is essential.

Figure 3 explains how to choose proper reference values, under assumption that waveforms are sinusoidal and in the steady state, their derivative is zero. Then, the reference voltage components, taken from Eq. (2), are described by Eqs. (10) and (11).

$$
\begin{aligned}
& u_{c x}^{*}=e_{g x} \\
& u_{c y}^{*}=-\omega_{g} L i_{g x}^{*}
\end{aligned}
$$

a)

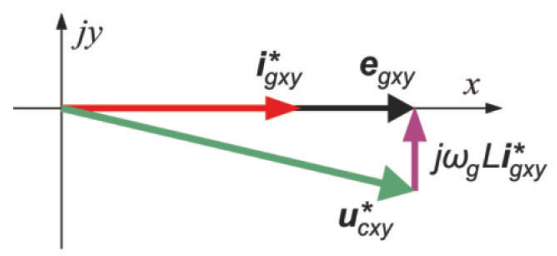

b)

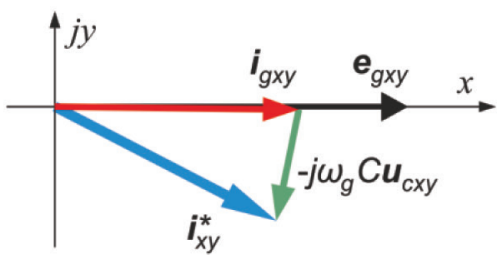

Fig. 3. Graphical explanation of reference values $u_{c y}^{*}$ (a) and $i_{x y}^{*}$ (b) according to Eqs. (10)-(12)

The rectifier current reference value is taken from Eq. (3) and indicated in Eq. (12).

$$
\boldsymbol{i}_{x y}^{*}=\boldsymbol{i}_{g x y}-j \omega_{g} C \boldsymbol{u}_{c x y}
$$

To predict the value of the capacitor voltage components, it is necessary to use Eq. (3) for finding the connection between the chosen rectifier current vector $i_{x y}$ and the behaviour of the capacitor voltage vector.

$$
\frac{d \boldsymbol{u}_{c x y}}{d t}=\frac{1}{C}\left(\boldsymbol{i}_{g x y}-\boldsymbol{i}_{x y}-j \omega_{g} C \boldsymbol{u}_{c x y}\right)=\frac{1}{C}\left(\boldsymbol{i}_{x y}^{*}-\boldsymbol{i}_{x y}\right)
$$

The expected change in the filter voltage components in the $k+1$ moment, after one sample period $T_{s}$, can be computed from Eq. (14) using measurements taken in the $k$-th moment.

$$
\Delta \boldsymbol{u}_{c x y}(k+1)=\frac{d}{d t} \boldsymbol{u}_{c x y} T_{s}=\Delta u_{c x}(k+1)+j \Delta u_{c y}(k+1)
$$


Equation (15) describes the predicted voltage vector.

$$
\boldsymbol{u}_{c x y}(k+1)=\boldsymbol{u}_{c x y}(k)+\Delta \boldsymbol{u}_{c x y}(k+1)
$$

The DC current value decides the amount of the energy transferred to the load. It changes in the way shown in Eq. (16).

$$
\frac{d i_{D C}}{d t}=\frac{1}{L_{D C}}\left(u_{D C}-R_{D C} i_{D C}\right)
$$

The predicted value of the DC current is expressed in Eq. (17).

$$
i_{D C}(k+1)=i_{D C}(k)+\Delta i_{D C}(k+1)
$$

The whole algorithm is explained in Fig. 4.

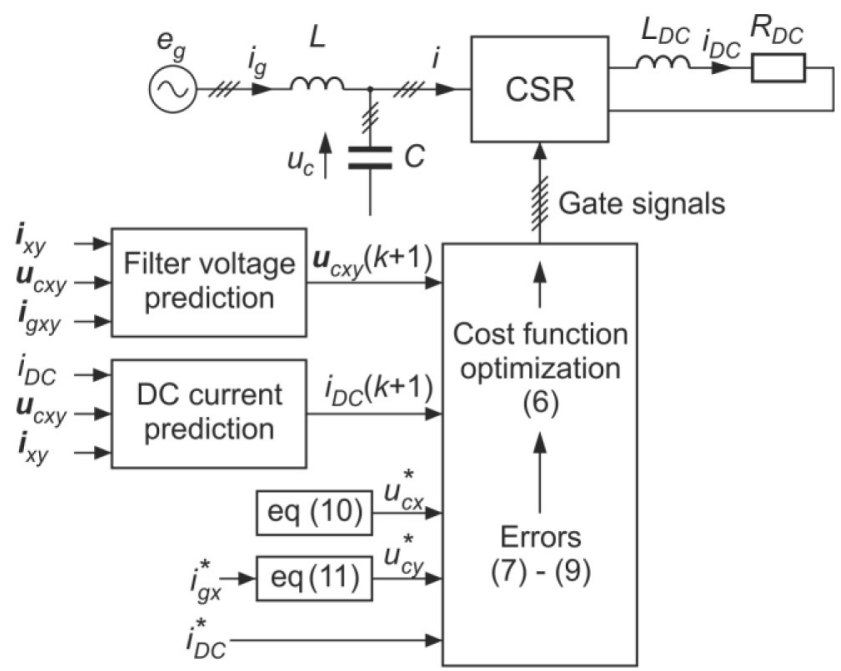

Fig. 4. Diagram of FCS-MPC algorithm

\section{Results}

Validation of the proposed FCS-MPC algorithm has been performed by means of MatLab/Simulink. The algorithm operates with a sample time of $T_{s}=50 \mu \mathrm{s}$. The parameters of the circuit are given in Tab. 1. The grid has $400 \mathrm{~V}$ and $50 \mathrm{~Hz}$ phase-to-phase voltage.

Table 1. Current source rectifier circuit parameters

\begin{tabular}{lcc}
\hline Name & Unit & Value \\
\hline \hline Load resistance, $R_{D C}$ & $\omega$ & 25 \\
DC bus inductance, $L_{D C}$ & $\mathrm{mH}$ & 4.32 \\
Filter inductance, $L$ & $\mathrm{mH}$ & 4 \\
Filter capacitance, $C$ & $\mu \mathrm{F}$ & 30 \\
\hline
\end{tabular}


The configuration described above has been tested in steady operation as well as in transient operation under a step change of $i_{D C}^{*}$. Figure 5 presents the situation wherein, at time $0.065 \mathrm{~s}$, the reference value decreases from $15 \mathrm{~A}$ to $12 \mathrm{~A}$.

Static performance proves that the power factor equals one and that filter oscillations in the grid current are damped. Transient operation lasts less than one grid period, and the response is stable.

The results of the fast Fourier transform (FFT) analysis (grid current sampling equals $1 \mu \mathrm{s}$ ), which demonstrate the harmonic amplitudes with reference to the fundamental frequency, are shown in Figs. 6 and 7.
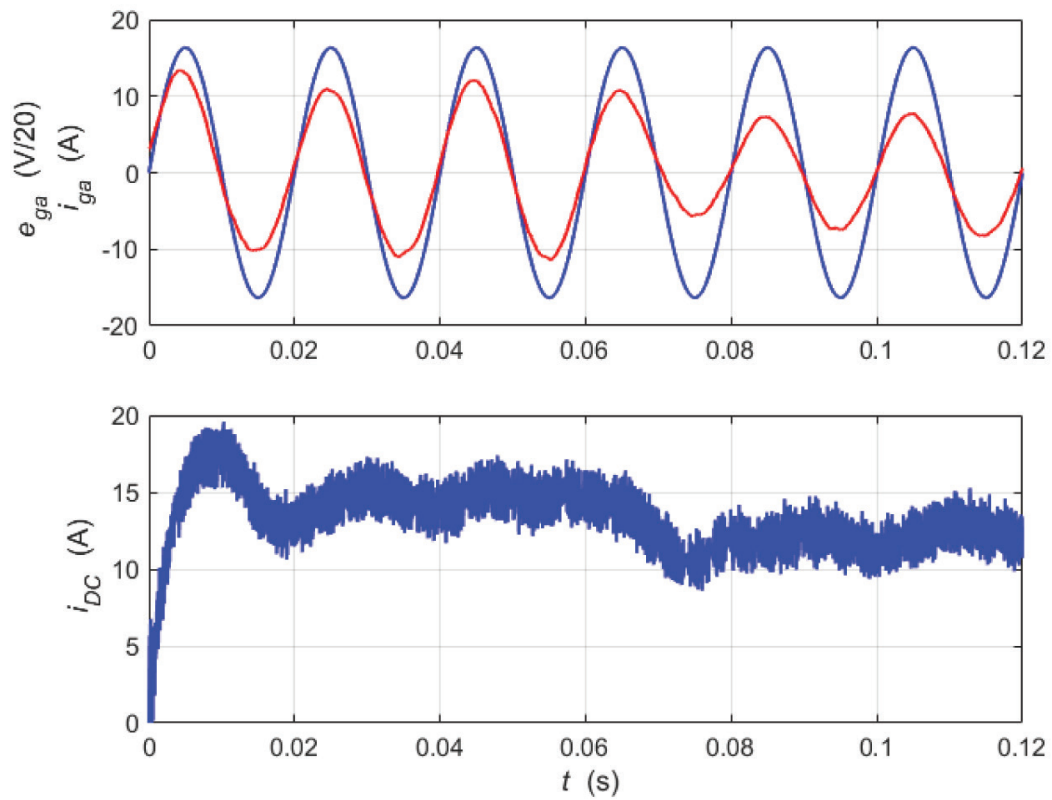

Fig. 5. Source voltage (blue), grid phase current (red) and load current under the step change of the reference

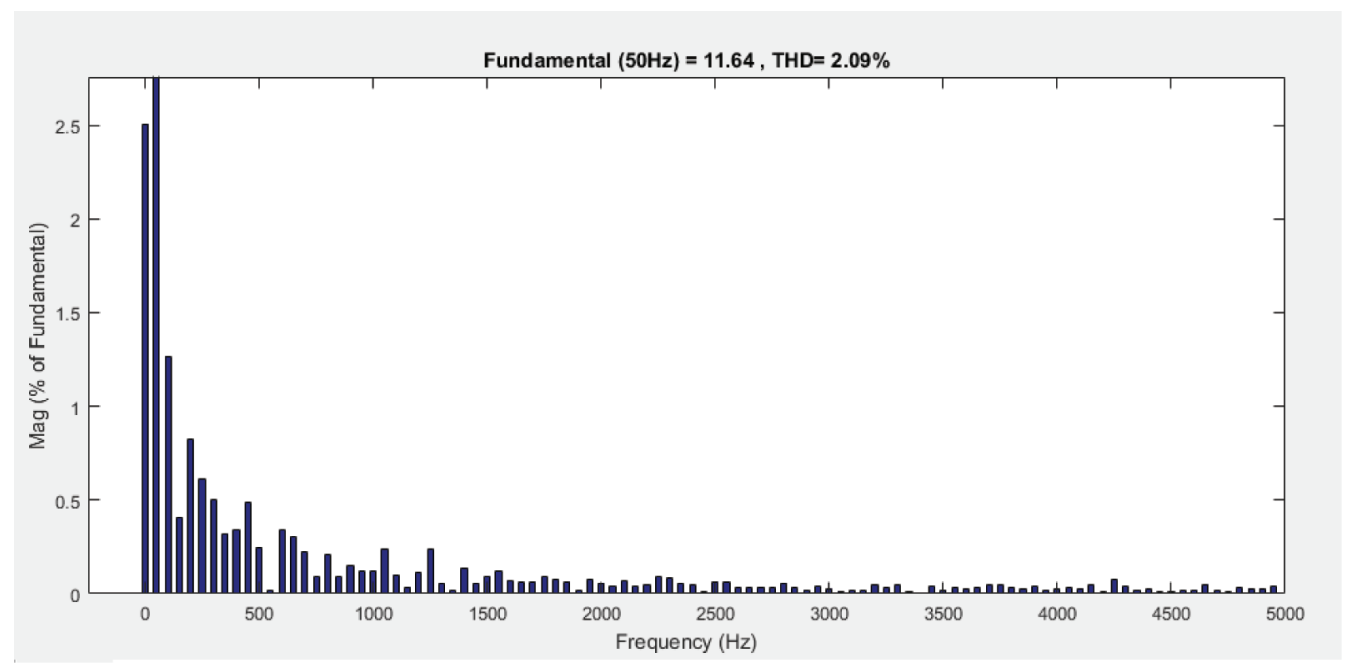

Fig. 6. FFT analysis of the grid current for $i_{D C}^{*}=15 \mathrm{~A}$

The damping effect is confirmed. Only the fifth, sixth and seventh harmonics have some influence on the current waveform; however, their amplitude is $<2 \%$ of the fundamental frequency. Total harmonic distortion (THD) has a higher value when the reference current is lower (Fig. 7), because the more frequent use of zero vectors leads to increase in the influence of the capacitor currents. 


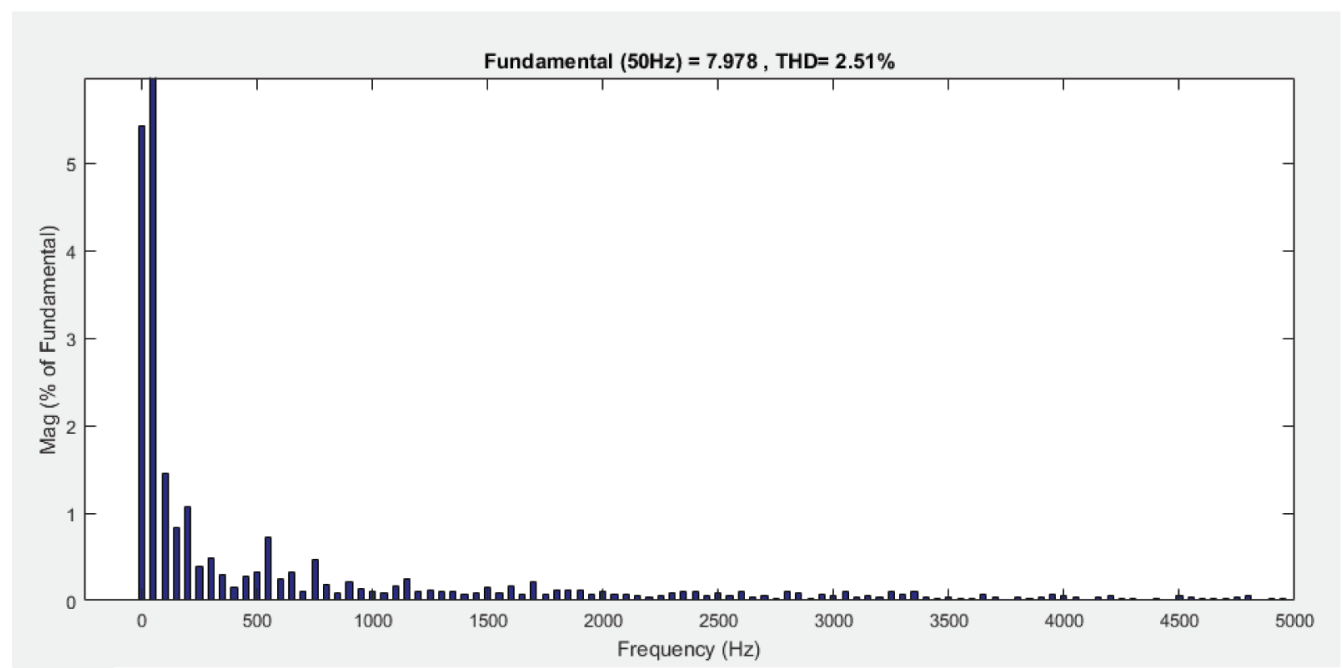

Fig. 7. FFT analysis of the grid current for $i^{*}{ }_{D C}=12 \mathrm{~A}$

\subsection{Disturbances in the grid}

Examination of the current source rectifier behaviour has been conducted under distorted grid voltage and grid voltage drop. The distortion was the injection of the fifth and seventh harmonics.

First, the operation illustrated in Fig. 5, wherein at time $0.065 \mathrm{~s}$, the reference value decreases from $15 \mathrm{~A}$ to $12 \mathrm{~A}$, was repeated, but at $0.02 \mathrm{~s}$, the grid voltage starts to be disturbed. The amplitude of the fifth harmonic is $5 \%$ and that of the seventh harmonic is $3 \%$ of the fundamental frequency, and the results are presented in Fig. 8 . Figs. 9 and 10 show the results of the FFT analysis.

The grid current waveform has changed slightly, and the THD has increased to about $1.1 \%$ in the worst case (Fig. 10). The fifth and seventh harmonics of the current have a bit higher amplitude, but overall, they are damped (Figs. 9 and 10). Only the DC current has higher oscillations; however, the mean value and dynamics stayed the same (Fig. 8).
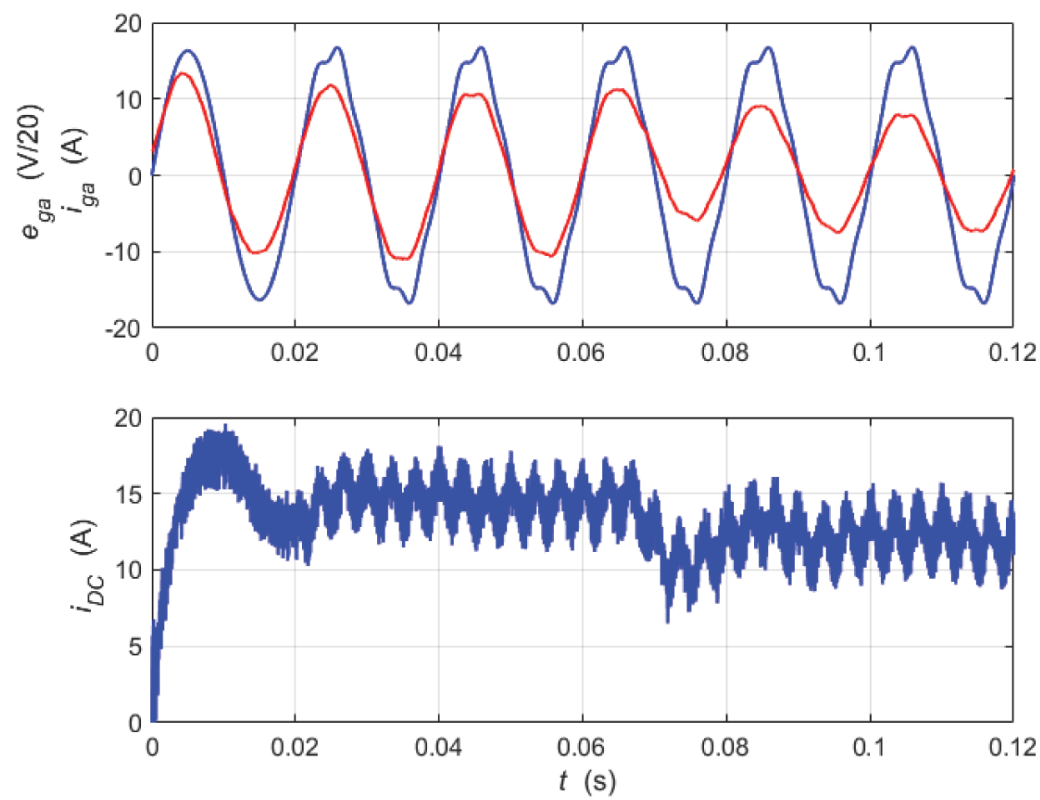

Fig. 8. Source voltage (blue), grid phase current (red) and load current under the step change of the reference and grid voltage distortion (5\% for the fifth harmonic and $3 \%$ for the seventh harmonic) 


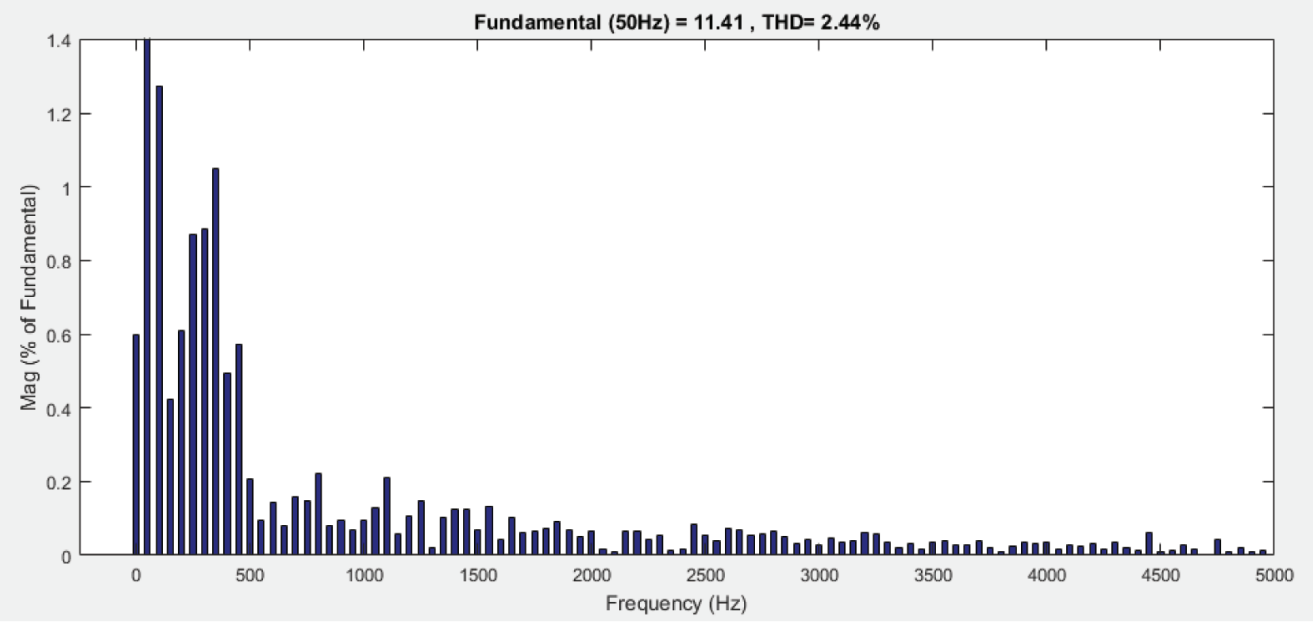

Fig. 9. $\mathrm{FFT}$ analysis of the grid current for $i_{D C}^{*}=15 \mathrm{~A}$

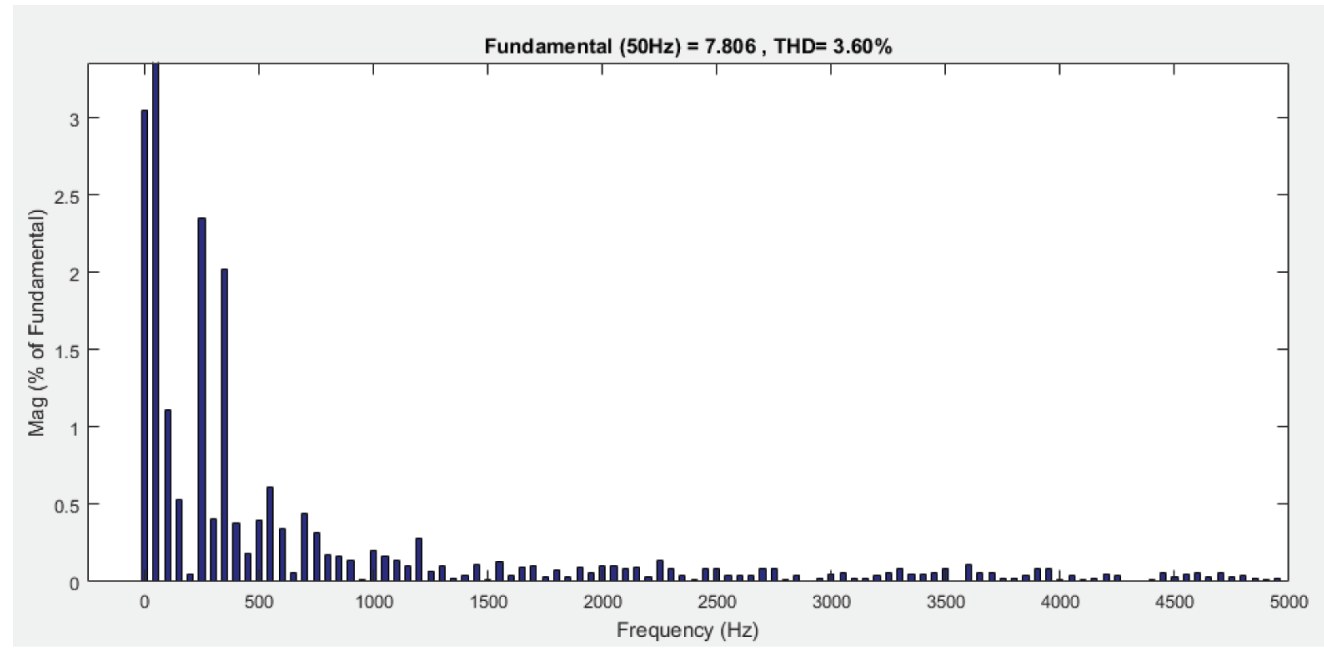

Fig. 10. FFT analysis of the grid current for $i^{*}{ }_{D C}=12 \mathrm{~A}$

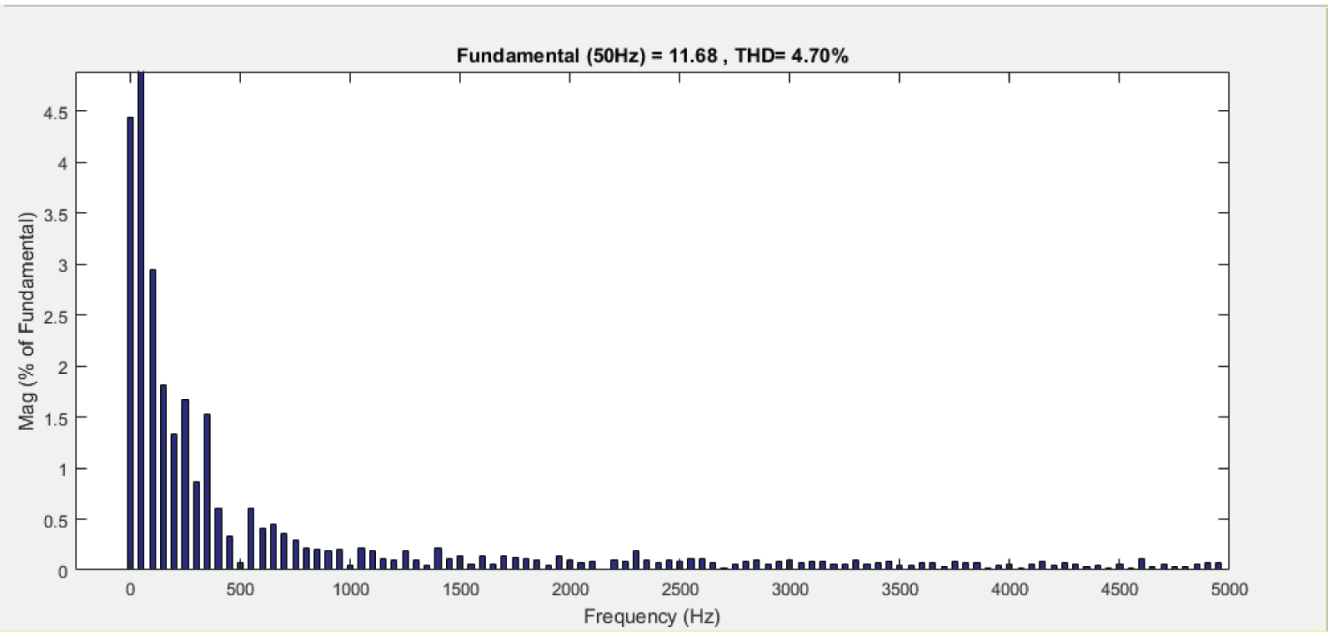

Fig. 11. FFT analysis of the grid current for $i^{*}{ }_{D C}=15 \mathrm{~A}$ 
To examine the influence of the weighting factors, they were decreased twice. The outcome of the FFT analysis is given in Fig. 11. The THD is doubled, and the amplitudes of the fifth and seventh harmonics are doubled but $<2 \%$ of the fundamental frequency.

Second, the harmonic injection increased, and both fifth and seventh harmonics have an amplitude equal to $10 \%$ of the fundamental frequency. The outcomes are illustrated in Figs. 12 and 13.

In these conditions, the grid current THD is almost four times higher than in a normal operation. Nevertheless, oscillations are damped, and the amplitude of the harmonics is smaller, ending at 3.5\% (Fig. 12).

Third, the amplitudes of the harmonics are saved, but the fifth harmonic increases the phase shift. The results are shown in Figs. 14 and 15.

Figures 14 and 15 convince that the phase shift of the voltage harmonics has a great impact on the grid current. The THD increases because the voltage distortions are located in the maximum of the waveform. The control
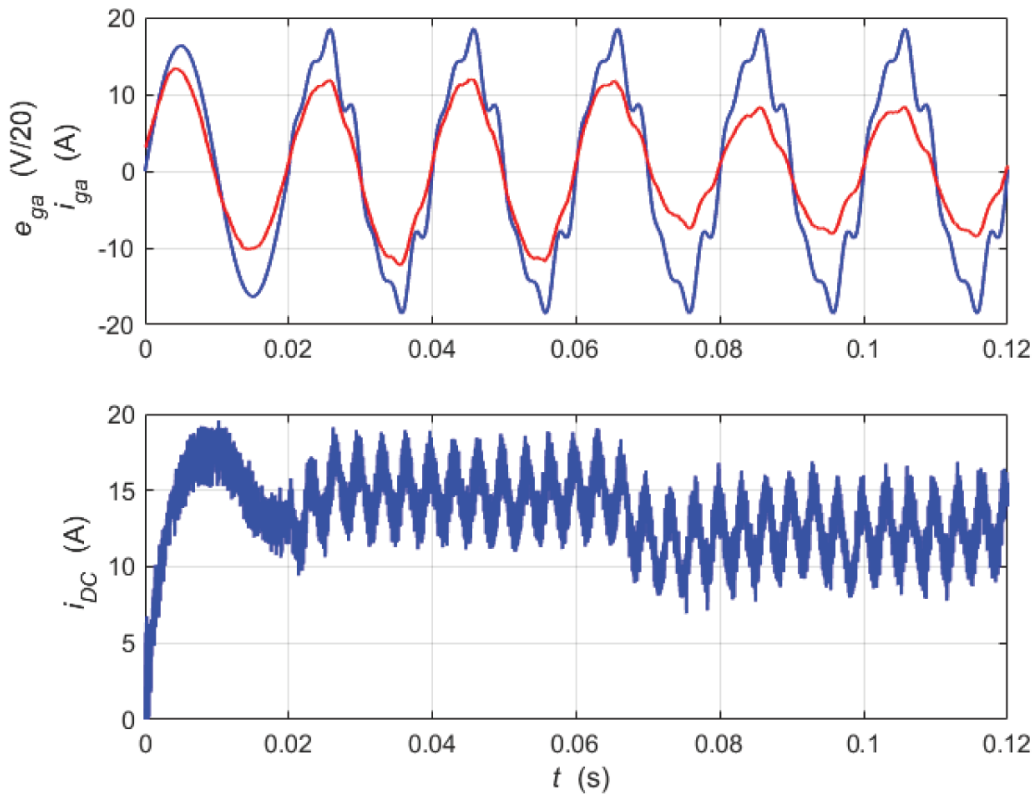

Fig. 12. Source voltage (blue), grid phase current (red) and load current under the step change of the reference and grid voltage distortion (10\% for fifth harmonic and $10 \%$ for seventh harmonic)

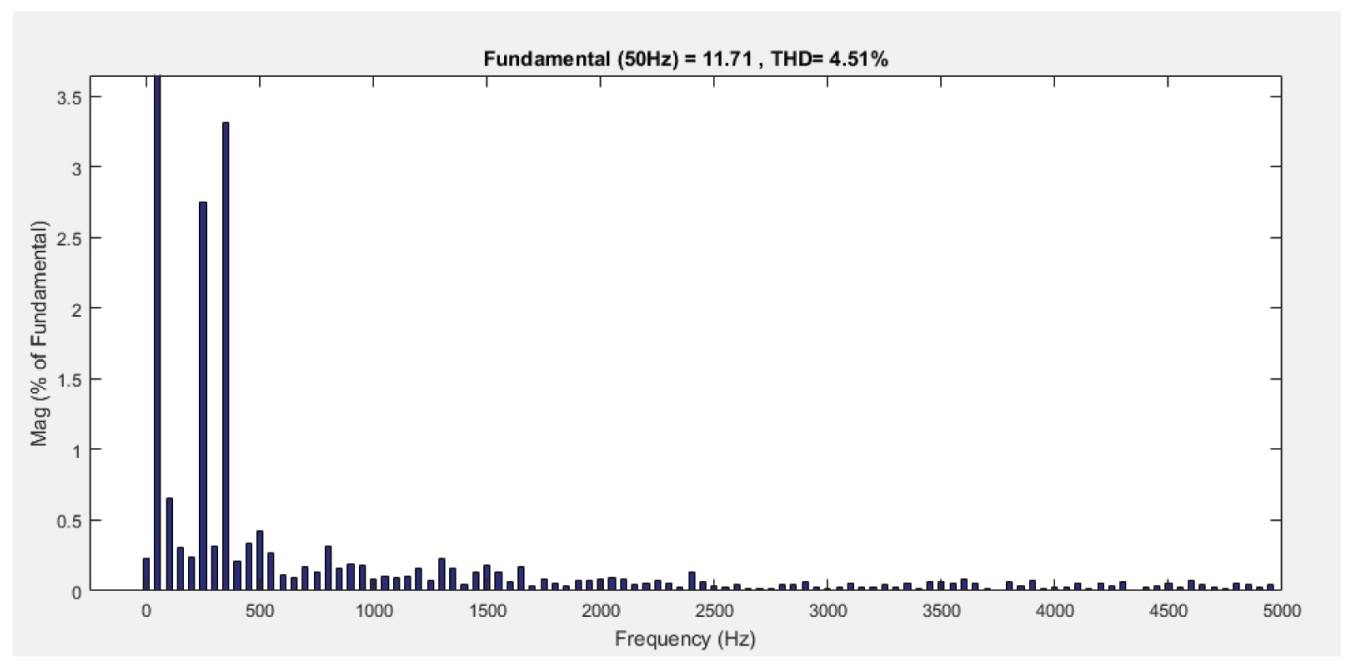

Fig. 13. FFT analysis of the grid current for $i^{*}{ }_{D C}=15 \mathrm{~A}$ 

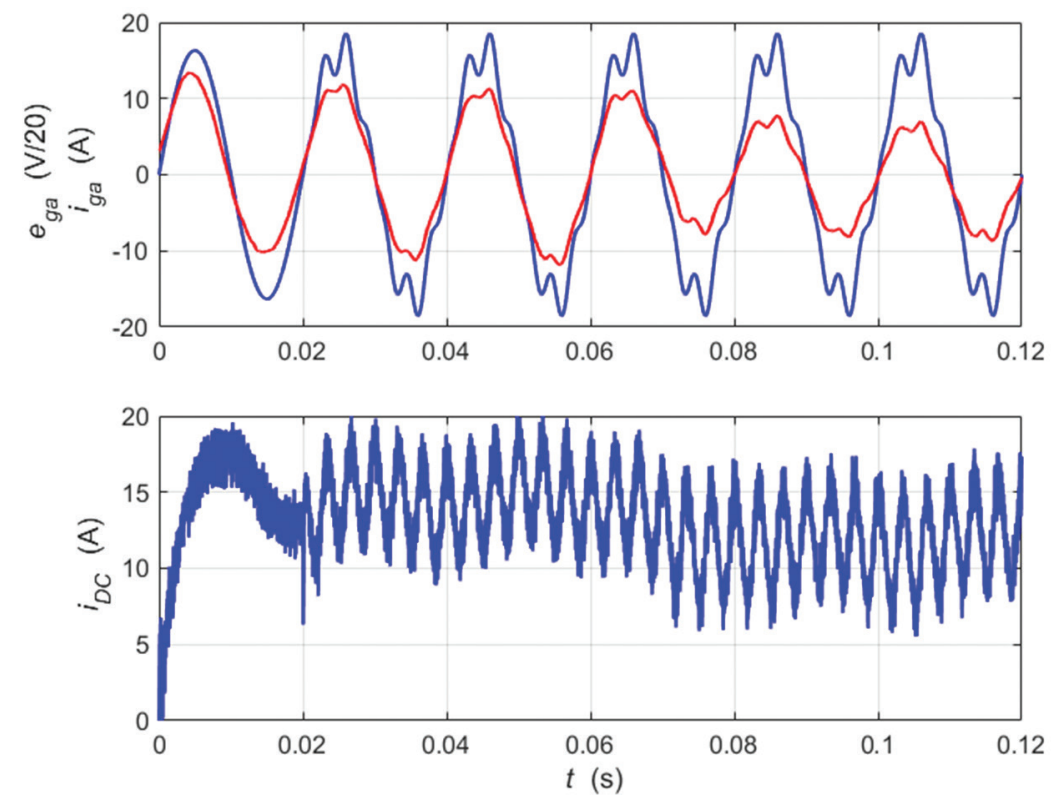

Fig. 14. Source voltage (blue), grid phase current (red) and load current under the step change of the reference and grid voltage distortion (phase shift and $10 \%$ for fifth harmonic, and $10 \%$ for seventh harmonic)

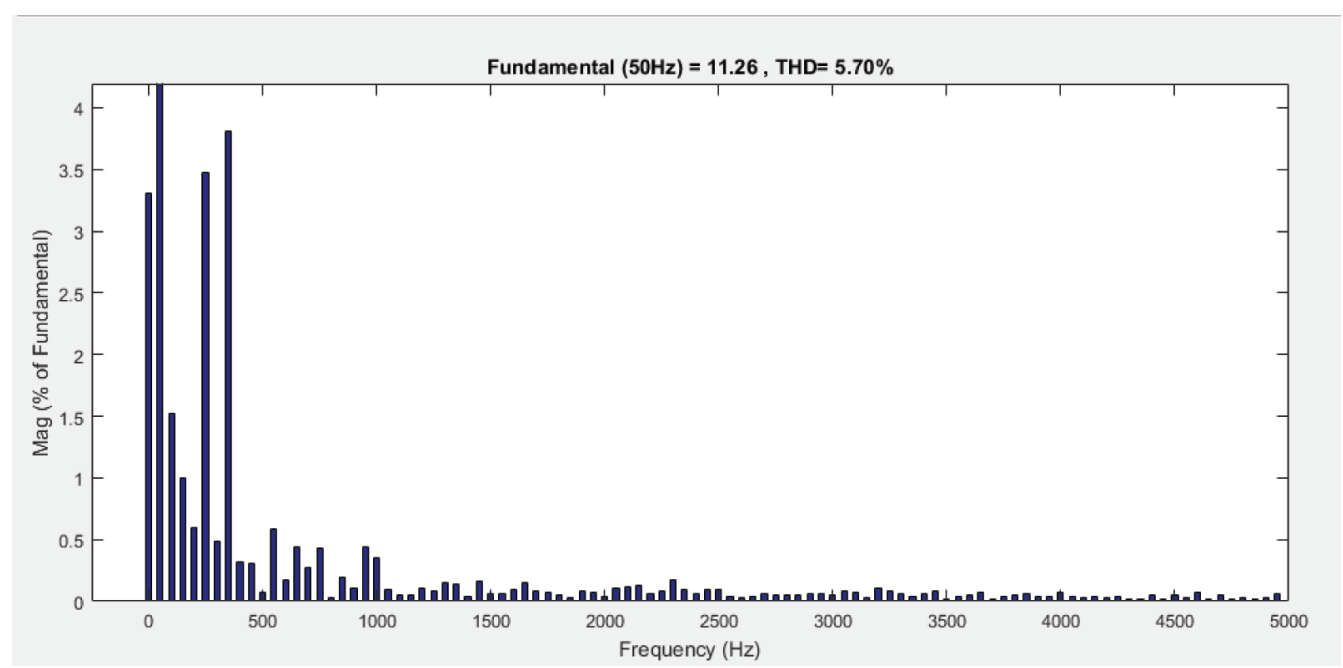

Fig. 15. FFT analysis of the grid current for $i_{D C}^{\star}=15 \mathrm{~A}$

ensures that the capacitor voltage is sinusoidal and, therefore, the difference of the grid voltage and capacitor voltage is given to the grid inductance. Peaks of the inductance voltage lead to the grid current distortions.

Finally, the experiment of the grid voltage drop is investigated. The reference is constant $i_{D C}^{*}=12 \mathrm{~A}$ and, at time $0.025 \mathrm{~s}$, the voltage drops to $80 \%$ of the nominal value, which is illustrated in Fig. 16 . The converter deals with this disturbance in a period of time shorter than one grid period.

\section{Conclusions}

The whole investigation presented in the paper allows us to conclude that the FCS-MPC method chosen for the converter is a good option to preserve unity power factor and damp higher harmonics of the grid current. Results 

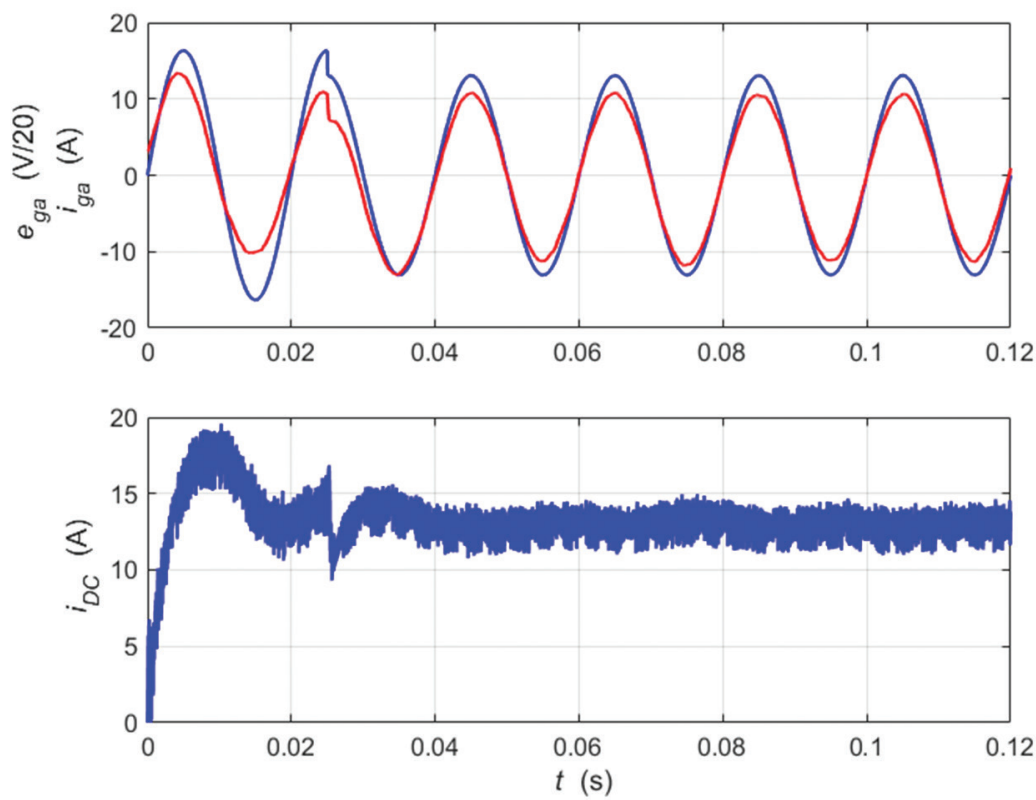

Fig. 16. Source voltage (blue), grid phase current (red) and load current in steady and transient states under $20 \%$ voltage drop at $0.025 \mathrm{~s}$

confirm that under disturbed grid voltage, the current source rectifier operates correctly and prevents the fifth and seventh harmonic amplitudes from rising above $4 \%$ of the fundamental frequency. Generally, distortions of the grid current are lower than distortions of the grid voltage, which is a consequence of the control algorithm response.

Application of such an algorithm demands the careful choice of the weighting factors. For different configurations and loads, the values of the weighting factors as well as the cost function equation may alter. It is important to decide which waveforms should be shaped precisely and which values need to be predicted, because it may reduce the damping effect.

\section{References}

Correa, P., Rodriguez, J., Lizama, I. and Andler, D. (2009). A Predictive Control Scheme for CurrentSource Rectifiers, IEEE Transaction on Industrial Electronics, 56(5), pp. 1813-1815.

Cortes, P., Kouro, S., La Rocca, B., Vargas, R., Rodriguez, J., Leon, J., Vazquez, S.and Franquelo, L. (2009). Guidelines for weighting factors design in model predictive control of power converters and drives. In: IEEE International Conference on Industrial Technology (ICIT), February 2009, Gippsland, Australia, pp. 1-7.

Falkowski, P., Kulikowski, K. and Grodzki, R. (2017). Predictive and Look-Up Table Control Methods of a Three-Level AC-DC Converter Under Distorted Grid Voltage. Bulletin of Polish Academy of Sciences Technical Sciences, 65(5), pp. 609-618.

Falkowski, P. and Sikorski, A. (2016). Dead-time compensation in a new FCS-MPC of an AC/DC converter with a LCL filter. In: 13th Selected Issues of Electrical Engineering and Electronics (WZEE 2016), Rzeszow 2016, pp. 1-6.

Feroura, H., Krim, F., Talbi, B., Laib, A. and Belaout, A. (2017). Finite-Set Model Predictive Direct Power Control of Grid Connected Current Source Inverter. Elektronika ir Elektrotechnika, 23(5), pp. 36-40.

Godlewska, A., Grodzki, R., Falkowski, P., Korzeniewski, M., Kulikowski, K. and Sikorski, A. (2017). Advanced control methods of DC/AC and AC/DC power converters - look-up table and predictive algorithms. In: J. Kabziński, ed., Advanced Control of Electrical Drives and Power Electronic Converters. Cham: Springer International Publishing, pp. 221-302.

Ibrahim, A. O. and EL-Fouly, T. H. M. (2009). A Control Method of Grid-Connected PWM Voltage Source Inverters to Mitigate Fast Voltage Disturbances. IEEE Transactions on Power Systems,24(1), pp. 489-491. 
Lammert, G., Heß, T., Schmidt, M., Schegner, P. and Braun, M. (2014). Dynamic grid support in low voltage grids - fault ride-through and reactive power/voltage support during grid disturbances. In: 2014 Power Systems Computation Conference, 18-22 August, Wroclaw, pp. 1-7.

Li, Y. W., Wu, B., Zargari, N. R., Wiseman, J. C. and Xu, D. (2007). Damping of PWM Current-Source Rectifier Using a Hybrid Combination Approach. IEEE Transaction on Power Electronics, 22(4), pp. 1383-1393.

Michalík, J., Peroutka, Z. and Šmídl, V. (2016). Finite control set MPC of active current-source rectifier with full state space model. In: Industrial Electronics Society IECON 2015 - 42nd Annual Conference of the IEEE, November 2016, Yokohama, pp. 4121-4126.

Naguib, M. F. and Lopes, L. A. C. (2009). Minimize LowOrder Harmonics in Low-Switching-Frequency Space-Vector-Modulated Current Source Converters With Minimum Harmonic Tracking Technique. IEEE Transaction on Power Electronics, 24(4), pp. 881-893.
Noguchi, T. and Sano, K. (2007). Specific harmonic power suppression of direct-power-controlled current-source PWM rectifier. In: 7th International Conference on Power Electronics and Drive Systems (PEDS), 2007, pp. 1436-1441.

Salo, M. and Tuusa, H. (2000). A Vector Controlled Current-Source PWM Rectifier with a Novel Current Damping Method. IEEE Transaction on Industrial Electronics, 15(3), pp. 464-470.

Yuan, Z., Zhang, H., Shi, F., Ma, Ch. and Liu, G. (2017). Coupling characteristics and mechanism of the dynamic behaviors of high and low voltage power grid. In: 2nd International Conference on Power and Renewable Energy, 20-23 September 2017, Chengdu, pp. 1007-1012.

Zavala, P., Rivera, M., Kouro, S., Rodriguez, J., Wu, B., Yaramasu, V., Baier, C., Munoz, J., Espinoza, J. and Melin, P. (2013). Predictive control of a current source rectifier with imposed sinusoidal input currents. In: IECON 2013 - 39th Annual Conference of the IEEE Industrial Electronics Society, 10-13 November 2013, pp. 5842-5847. 